\title{
Accuracy of lymphocyte counts from UniCel DxH 800 in $\beta$-thalassemia/HbE patients having various numbers of nucleated red blood cells
}

\author{
Sunil Timilsena, ${ }^{1,3}$ Sakkarin Ardsiri, ${ }^{2}$ Surada Lerdwana, ${ }^{3}$ Krishna Das Manandhar, ${ }^{1}$ Kovit Pattanapanyasat, ${ }^{3}$ Egarit Noulsri ${ }^{4}$
}

\begin{abstract}
Background: The UniCel ${ }^{\circ} \mathrm{DxH}-800$ is an automated cell counter widely used in laboratories. However, the effects of increased nucleated red blood cells (NRBCs) on the lymphocyte counts obtained using the UniCel DxH-800 have not been fully elucidated.
\end{abstract}

Objective: The study's objective was to compare lymphocyte counts obtained using the DxH-800 and those obtained using flow cytometry in various ranges of NRBCs.

Methods: This cross-sectional study analyzed 25 healthy volunteers and $69 \beta$-thalassemia/HbE patients. The numbers of lymphocytes were determined using a UniCel DxH-800 and a standard flow cytometer using counting beads.

Results: In healthy volunteers, regression analysis of the lymphocyte counts using the two approaches showed an $\mathrm{r}^{2}$ 0.85 and a $p<0.0001$, and a Bland-Altman plot showed mean bias of +264 cells $/ \mu \mathrm{L}$. In $\beta$-thalassemia/HbE patients, regression analysis of the lymphocyte counts obtained using an automated cell counter and a flow cytometer showed an $\mathrm{r}^{2}$ of 0.06 , a $p=0.028$, and a Bland-Altman plot showed the mean bias of $+1,509$ cells $/ \mu \mathrm{L}$. In addition, a high degree of discrepancy in the lymphocyte counts was observed in $\beta$-thalassemia/HbE patients who had NRBCs $>100,001$ cells/ $\mu \mathrm{L}$.

Conclusions: The present study demonstrated that the UniCel DxH-800 performed well in enumerating lymphocytes in specimens that contained various numbers of NRBCs. However, a high number of NRBCs may interfere with lymphocyte counts obtained using the counter.

Key words: automated cell counter, nucleated red blood cell, lymphocyte, flow cytometry, $\beta$-thalassemia

\section{Citation:}

Timilsena, S., Ardsiri, S., Lerdwana, S., Manandhar, K. D., Pattanapanyasat, K., Noulsri, E. (2022). Accuracy of lymphocyte counts from UniCel DxH 800 in $\beta$-thalassemia/HbE patients having various numbers of nucleated red blood cells. Asian Pac J Allergy Immunol, 40(2), 187-193. https://doi.org/10.12932/ap170119-0472

\section{Affiliations:}

Central Department of Biotechnology, Tribhuvan University, Kathmandu, Nepal

${ }^{2}$ Department of Pediatrics, Faculty of Medicine Siriraj Hospital, Mahidol University, Bangkok, Thailand

Department of Research and Development, Faculty of Medicine Siriraj Hospital, Mahidol University, Bangkok, Thailand

${ }^{4}$ Research Division, Faculty of Medicine Siriraj Hospital,

Mahidol University, Bangkok, Thailand

\section{Corresponding author:}

Egarit Noulsri

Research Division, Faculty of Medicine, Siriraj Hospital,

Mahidol University, Bangkok 10700, Thailand

E-mail: egarit.nou@mahidol.ac.th

$\begin{array}{ll}\text { Abbreviations: } \\ \text { NRBC } & \text { nucleated red blood cell } \\ \text { FSC } & \text { forward scatter } \\ \text { SSC } & \text { side scatter } \\ \text { LOA } & \text { limit of agreement } \\ \text { WBC } & \text { white blood cell }\end{array}$

\section{Introduction}

Lymphocytes are one of the white blood cell subtypes in the immune system. They are classified into T, B and natural killer (NK) cells, according to the specific marker expressed on the surface membrane. The primary function of T-lymphocytes is to mediate the cellular immunity while B-lymphocytes 
are responsible for humoral immunity. ${ }^{1,2}$ Once lymphocytes have identified a pathogen or pathogen-infected cells, they generate immune responses to eliminate the "non-self" invader. As part of the innate immune cells, NK cells show a cytolytic function against tumors and virus-infected cells. ${ }^{3} \mathrm{~A}$ lymphocyte count is normally part of a peripheral complete blood count and is expressed as the percentage of lymphocytes to the total number of white blood cells. It is now widely acknowledged that an increase in lymphocyte concentration is normally associated with inflammation in patients, while low absolute lymphocyte count is associated with increased rates of infection after trauma or surgery. ${ }^{4,5}$ Considering this association, accuracy of lymphocyte enumeration is essential for clinical managements of these patients.

Nucleated red blood cells (NRBCs) are normoblasts that fail to exclude the nuclei before exiting from the bone marrow or liver. These NRBCs are usually found in the peripheral blood circulation of patients who have severe anemia, extramedullary erythropoiesis, and splenectomy. ${ }^{6,7}$ In severe $\beta$-thalassemia patients, cell-counter analysis has demonstrated that the number of NRBCs can increase to 500 cells/100 white blood cells (WBCs). ${ }^{8}$ Considering the similarity in size between NRBCs and lymphocytes, the increase in non-lysis NRBCs in the blood circulation might interfere with the lymphocyte count obtained using an automated cell counter. ${ }^{9-11}$

Lymphocyte enumeration can be performed using several approaches, but the most widely used methods are flow cytometry and automated cell counters. ${ }^{12,13}$ Flow cytometry first identifies the total populations of WBCs using monoclonal antibodies, and then granulocytes, monocytes, and lymphocytes are classified according to size and internal complexity. In addition, the number of cells can be calculated using the reference microbeads, which have known concentrations. Studies have demonstrated the accuracy of this approach for enumerating WBCs in blood samples that have a high number of NRBCs. ${ }^{14}$ The market includes many modern instruments for performing automated cell counting. The UniCel ${ }^{\infty}$ DxH-800 from Beckman Coulter is one of the automated cell counters most widely used in medical laboratories. ${ }^{15-18}$ This automated cell counter includes new electronic and mechanical designs and uses advanced algorithm technology to analyze complete blood counts (CBCs), WBCs differentials, NRBCs, and reticulocytes. Studies have evaluated the instrument's performance. ${ }^{19-22}$ However, the effect of NRBCs on lymphocyte counts conducted using the UniCel DxH-800 has not been fully elucidated, particularly in patients with high NRBC counts.

In the current study, we compared the number of lymphocytes obtained using flow cytometry to the number obtained using a Beckman Coulter UniCel DxH-800 to evaluate the accuracy of this instrument when enumerating lymphocytes in $\beta$-thalassemia/HbE patients who had various numbers of NRBCs.

\section{Materials and Methods Materials}

The TriTest reagent, FACSLysing solution, and TruCount tube were purchased from Becton Dickinson (San Jose, CA, USA).

\section{Specimens}

The study was approved by the Institutional Reviewer Board of the Faculty of Medicine Siriraj Hospital, Mahidol University, Bangkok, Thailand. The patients were from the Department of Pediatrics, Faculty of Medicine Siriraj Hospital, Mahidol University. Patients' diagnoses were based on hemoglobin typing and molecular characterization. Patients with $\beta$-thalassemia provided written informed consent, after which, $3 \mathrm{~mL}$ of peripheral blood was collected from each into vacationer tubes containing $\mathrm{K}_{2}$ EDTA as an anticoagulant (Becton Dickinson; Franklin Lake, NJ, USA).

\section{Flow cytometry enumeration of lymphocytes}

First, 50 microliters of the blood sample were pipetted into a TruCount tube containing $20 \mu \mathrm{L}$ of TriTest reagents, and then the mixture was incubated in the dark at room temperature. After $15 \mathrm{~min}$ of incubation, $450 \mu \mathrm{L}$ of $1 \times$ FACSLysing solution was added to the tube, and it was incubated for 10 min. The samples were analyzed using a FACSCalibur (Becton Dickinson; San Jose, CA, USA).

For flow cytometry analysis, forward scatter (FSC) and side scatter (SSC) were set as the linear scale. The fluorescent parameters were set as the logarithmic scale. To eliminate debris and noise, the threshold was set at CD45. The lymphocytes and counting beads were identified and gated according to their SSC and CD45 characteristics. A minimum of 1300 events of the counting beads was set for acquisition. The number of lymphocytes was calculated according to the manufacturer's recommendation.

\section{Automated hematology analyzer}

Complete blood counts were evaluated using a UniCel DxH-800 (Beckman Coulter Inc.; Brea, CA, USA) according to the routine procedure used in the Department of Pediatrics, Faculty of Medicine, Siriraj Hospital. Before the samples were analyzed, both inter- and intra-laboratory quality controls were performed on the instrument.

\section{Corrected WBCs}

Blood smears were prepared and then stained with Wright-Giemsa (Miles Laboratories; Elkhart, IN, USA). In all, 200 cell WBC deferential counts were randomly performed using different slides and the two medical technologists. To determine their percentages, the NRBCs were counted microscopically using the laboratory's routine methods. Corrected WBCs were calculated using the following formula: corrected $\mathrm{WBC} / \mu \mathrm{L}=($ estimated $\mathrm{WBCs} / \mu \mathrm{L} \times 100) /(100+$ number of NRBCs in $100 \mathrm{WBCs}$ ).

\section{Statistical analysis}

The data were graphed and analyzed using GraphPad Prism version 5.0.1 (GraphPad Software, Inc.; San Diego, CA, USA). The results were expressed as mean \pm standard error (SE). Linear regression was used to determine the association between the number of WBCs and the lymphocyte counts obtained using the DxH-800 and those obtained using flow cytometry. A Bland-Altman test was used to address the bias between the two approaches. 


\section{Results}

Hematological parameters of healthy and $\beta$-thalassemia/HbE patients

In the present study, $69 \beta$-thalassemia/HbE patients and 25 healthy volunteers were analyzed. Table 1 summarizes the hematological data of all the subjects. The results showed that the $\mathrm{RBC}$ counts and $\mathrm{RBC}$ indices in the $\beta$-thalassemia/HbE patients were significantly lower than those in the healthy volunteers. In contrast, the RDWs, WBC counts, lymphocytes, and platelets in the $\beta$-thalassemia/HbE patients were significantly higher than those in the healthy volunteers. In addition, the number of NRBCs/100 leukocytes in $\beta$-thalassemia/ $\mathrm{HbE}$ patients ranged from 3-1766.

To investigate the accuracy of the NRBC counts, we compared the NRBC counts obtained using the DxH-800 with those obtained using the manual approach in $\beta$-thalassemia/ $\mathrm{HbE}$ patients. The results demonstrated an excellent correlation between the two methods, with an $\mathrm{r}^{2} 0.96$, a $\mathrm{y}=1.15 \mathrm{x}+$ 26.93, and a $p<0.0001$ (Figure 1A). A Bland-Altman analysis showed a mean bias of +52 cells $/ \mu \mathrm{L}$ and a limit of agreement (LOA) ranging from -372 to +226 cells/ $\mu \mathrm{L}$ (Figure 1B).

Correlation and agreement between lymphocyte counts obtained using DxH-800 and flow cytometry in healthy volunteers and $\beta$-thalassemia/HbE patients

Analysis of the results from healthy donors showed a good correlation $\left(\mathrm{r}^{2}=0.85, \mathrm{y}=0.8 \mathrm{x}+243.4, p<0.0001\right)$ between lymphocyte counts obtained using a UniCel DxH-800 and counts obtained using flow cytometry (Figure 2A). A Bland-Altman plot demonstrated a mean bias of +264 cells $/ \mu \mathrm{L}$ and an LOA that ranged from -536 to $+1,066$ cells/ $\mu \mathrm{L}$ (Figure 2B).

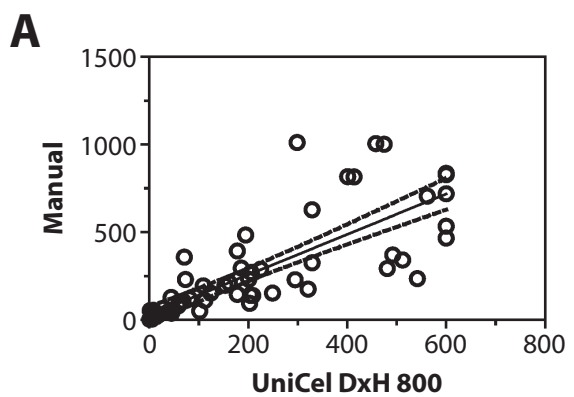

Table 1. Hematological data of healthy volunteers and $\beta$-thalassemia/HbE patients

\begin{tabular}{|c|c|c|c|}
\hline & $\begin{array}{l}\text { Healthy } \\
(n=25)\end{array}$ & $\begin{array}{c}\beta \text {-thalassemia/HbE } \\
(n=69)\end{array}$ & $p$-value \\
\hline $\begin{array}{l}\mathrm{RBC} \\
\left(\times 10^{6} / \mu \mathrm{L}\right)\end{array}$ & $\begin{array}{c}4.62 \pm 60287 \\
(4.12-5.39)\end{array}$ & $\begin{array}{c}3.42 \pm 63939 \\
(2.53-5)\end{array}$ & $<0.0001$ \\
\hline $\begin{array}{l}\text { Hemoglobin } \\
(\mathrm{g} / \mathrm{dL})\end{array}$ & $\begin{array}{l}13.28 \pm 0.25 \\
(10-17)\end{array}$ & $\begin{array}{l}7.94 \pm 0.17 \\
\quad(5-11)\end{array}$ & $<0.0001$ \\
\hline $\begin{array}{l}\text { Hematocrit } \\
(\%)\end{array}$ & $\begin{array}{c}39.25 \pm 0.68 \\
(32-50)\end{array}$ & $\begin{array}{c}25.48 \pm 0.47 \\
\quad(17-35)\end{array}$ & $<0.0001$ \\
\hline MCV (fL) & $\begin{array}{c}84.84 \pm 0.72 \\
(77-96)\end{array}$ & $\begin{array}{c}74.72 \pm 0.83 \\
(59-88)\end{array}$ & $<0.0001$ \\
\hline $\mathrm{MCH}(\mathrm{pg})$ & $\begin{array}{l}25.53 \pm 0.3 \\
(24-32)\end{array}$ & $\begin{array}{c}23.09 \pm 0.34 \\
(16-29)\end{array}$ & $<0.0001$ \\
\hline $\begin{array}{l}\text { MCHC } \\
(\mathrm{g} / \mathrm{dL})\end{array}$ & $\begin{array}{c}33.44 \pm 0.19 \\
(29-35)\end{array}$ & $\begin{array}{l}30.9 \pm 0.28 \\
\quad(24-35)\end{array}$ & $<0.0001$ \\
\hline RDW (\%) & $\begin{array}{l}13.97 \pm 0.2 \\
(12-17)\end{array}$ & $\begin{array}{l}26.16 \pm 0.81 \\
\quad(15-42)\end{array}$ & $<0.0001$ \\
\hline $\begin{array}{l}\text { Estimated } \\
\text { WBC }(/ \mu \mathrm{L})\end{array}$ & $\begin{array}{c}7,203 \pm 440 \\
(2,900-13,300)\end{array}$ & $\begin{array}{c}17,945 \pm 1,983 \\
(3,300-108,900)\end{array}$ & $<0.0001$ \\
\hline $\begin{array}{l}\text { Corrected } \\
\text { WBC }(/ \mu \mathrm{L})\end{array}$ & - & $\begin{array}{c}6,396 \pm 414 \\
(1,676-15,825)\end{array}$ & - \\
\hline $\begin{array}{l}\text { Lymphocyte } \\
(/ \mu \mathrm{L})\end{array}$ & $\begin{array}{c}2,807 \pm 197 \\
(1,400-5,700)\end{array}$ & $\begin{array}{c}6,080 \pm 793 \\
(700-41,200)\end{array}$ & 0.0077 \\
\hline Platelet $(/ \mu \mathrm{L})$ & $\begin{array}{c}252,938 \pm 13,812 \\
(103,000-572,000)\end{array}$ & $\begin{array}{l}480,274 \pm 27,074 \\
(42,900-988,000)\end{array}$ & 0.03 \\
\hline $\begin{array}{l}\text { NRBCs/ } \\
100 \mathrm{WBCs}\end{array}$ & 0 & $\begin{array}{l}256 \pm 45 \\
(3-1,766)\end{array}$ & - \\
\hline
\end{tabular}

Data represent mean \pm standard error $(\min -\max )$

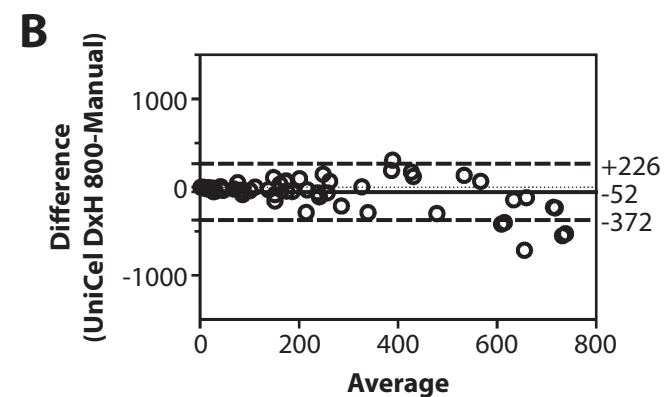

Figure 1. Regression (A) and Bland-Altman analysis (B) of NRBCs obtained using a UniCel DxH-800 and manual approach in $\beta$-thalassemia/HbE patients.
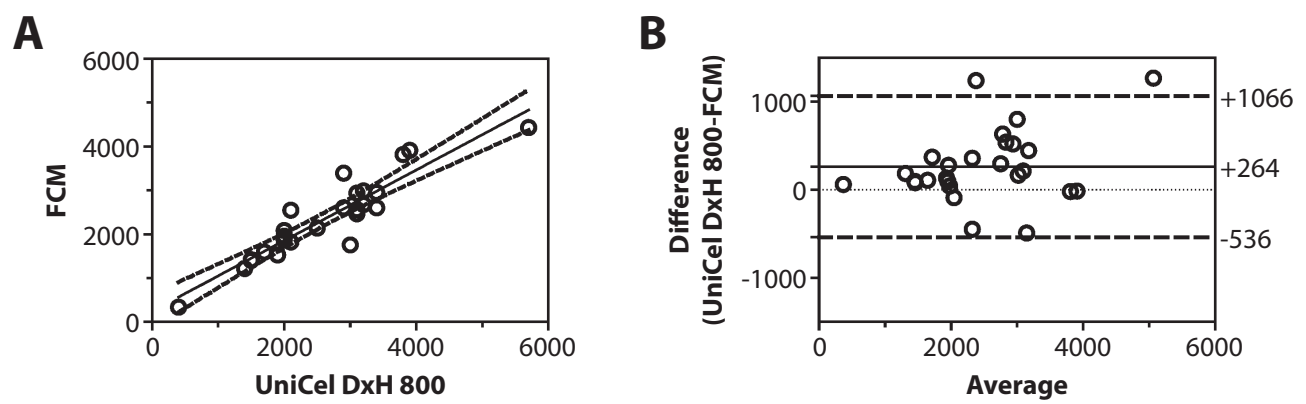

Figure 2. Regression (A) and Bland-Altman analysis (B) of lymphocytes obtained using a UniCel DxH-800 and standard flow cytometry in healthy volunteers. 
For the $\beta$-thalassemia/HbE patients, linear regression analysis showed an $\mathrm{r}^{2}=0.06$, a $\mathrm{y}=0.11 \mathrm{x}+3642$ and a $p=0.028$. The Bland-Altman analysis showed a mean bias and an LOA of $+1,509$ cells $/ \mu \mathrm{L}$ and ranging from $-11,684$ to $+14,704$ cells/ $\mu \mathrm{L}$. To further evaluate the effect of NRBC levels on lymphocyte counts obtained using the $\mathrm{DxH}-800$, the $\beta$-thalassemia/ $\mathrm{HbE}$ patients were first categorized into four groups according to the numbers of their NRBC counts, and then, for each group, the agreement of the lymphocyte counts obtained using the DxH-800 and the flow cytometer were compared. Our results showed that the patients whose NRBCs $>100,001$ cells $/ \mu \mathrm{L}$ showed the highest disagreement, having a mean bias of $+10,203$ cells $/ \mu \mathrm{L}$ and an LOA of $-9,138$ to $+29,546$ cells $/ \mu \mathrm{L}$ (Figure 3 ). In contrast, the other three groups (NRBCs < 1,000; 1,001-10,000; and 10,001-100,000 cells/ $\mu \mathrm{L})$ showed mean biases of +516 cells $/ \mu \mathrm{L} ;-3,335$ to $+4,368$ cells/ $\mu \mathrm{L},-578$ cells $/ \mu \mathrm{L} ;-3,962$ to $+2,805$ cells $/ \mu \mathrm{L}$, and -308 cells $/ \mu \mathrm{L}$;
$-8,694$ to $+8,078$ cells $/ \mu \mathrm{L}$, respectively. In addition, our Bland-Altman plots showed the values of the differences on both sides of the zero line for the groups having NRBCs < 1,$000 ; 1,001-10,000$; and 10,001-100,000 cells/ $\mu \mathrm{L}$. In contrast, a trend of positive bias, or over-estimation of lymphocyte count, was demonstrated in the group that had NRBCs > 100,001 cells/ $\mu \mathrm{L}$.

\section{Effect of NRBCs on identification of lymphocytes}

To investigate the effect of the number of NRBCs on the identification of lymphocytes, we compared the FSC and SSC characteristics of lymphocytes in blood specimens obtained from healthy volunteers and $\beta$-thalassemia/HbE patients. In specimens from healthy volunteers, the lymphocyte population was clearly separated from other leukocyte populations according to their CD45 intensities and FSC and SSC characteristics (Figure 4A). In specimens from $\beta$-thalassemia/ $\mathrm{HbE}$

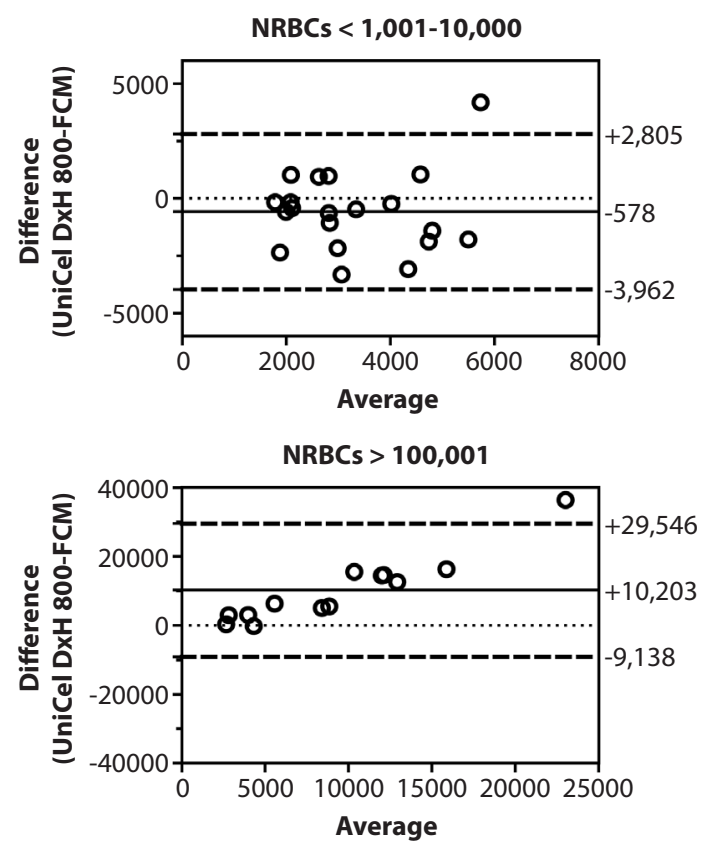

Figure 3. Bland-Altman plots showing the differences against the average of the lymphocyte counts obtained using the UniCel DxH-800 and a standard flow cytometer in $\beta$-thalassemia/HbE patients who have NRBCs $<1,000 ; 1,001-10,000$; 10,001-100,000; and > 100,001 cells/ $\mu \mathrm{L}$.
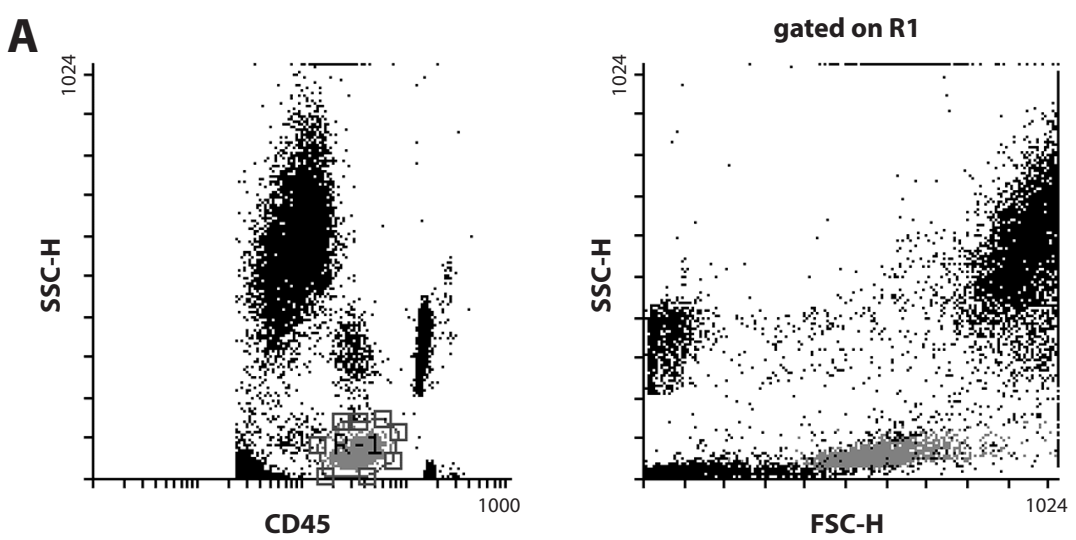

Figure 4. Effects of NRBCs on lymphocyte enumeration. CD45 vs. SSC and FSC vs. SSC dot plots showing the lymphocyte population (R1) in specimens from healthy volunteers (A) and $\beta$-thalassemia/HbE patients who had high numbers of NRBCs (B). 

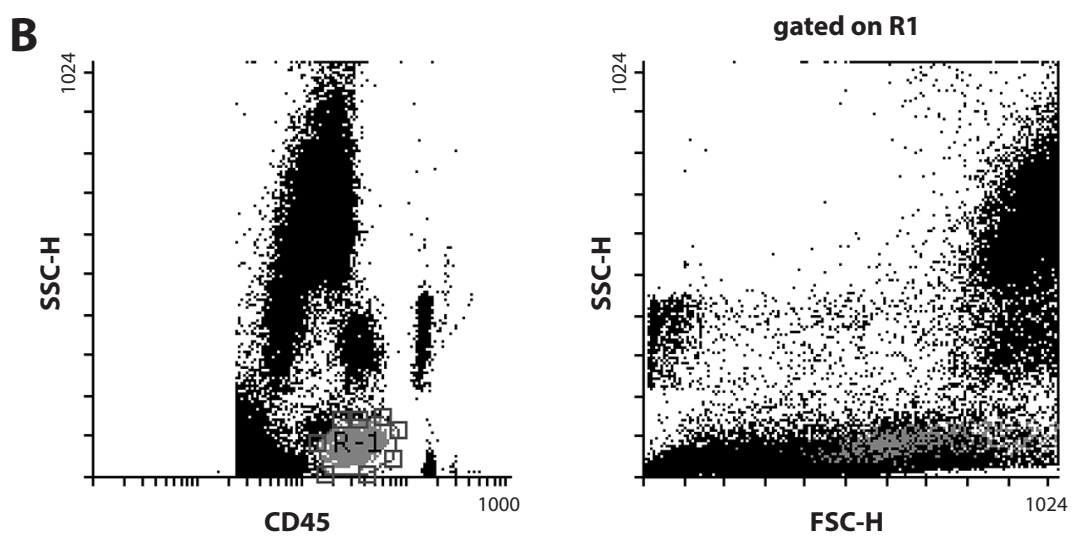

Figure 4. (Continued)

patients, the lymphocyte population could be classified using CD45 vs. SSC (Figure 4B). However, backgating analysis demonstrated the similarity of the FSC and SSC characteristics of the lymphocytes and the non-lysed NRBCs, suggesting an influence of the NRBCs on lymphocyte enumeration.

\section{Discussion}

The current investigation aimed to investigate the effects of NRBC levels on the accuracy of lymphocyte counts obtained using the Beckman Coulter UniCel DxH-800 in $\beta$-thalassemia/HbE patients. The results suggested the accuracy of lymphocyte counts using the instrument in both healthy volunteers and $\beta$-thalassemia/HbE patients. However, a high number of NRBCs was associated with a discrepancy in the lymphocyte counts obtained using the UniCel DxH-800 cell counter and standard flow cytometry.

$\beta$-thalassemia/ $\mathrm{HbE}$ is one of the most prevalent diseases in Thailand and other countries, and patients show varying degrees of anemia and abnormally high numbers of NRBCs. ${ }^{23-26}$ The increased number of NRBCs in severe $\beta$-thalassemia/HbE has been shown to interfere with the lymphocyte counts obtained using several automated cell counters. ${ }^{9,10}$ Barnes et al. evaluated the performance of the $\mathrm{DxH}-800$ on the detection of blast cells and found that its false positive rate when differentiating white blood cells in abnormal specimens was lower than that of another automated instrument. ${ }^{16}$ Studies have also suggested the high sensitivity and specificity of platelet and white blood cell counts and the low NRBC false negative rate of DxH-800 differentiation. ${ }^{17}$ In addition, evaluation of pediatric specimens has demonstrated an excellent correlation among white blood cell counts, RBCs, platelets, and hematological parameters obtained using both the $\mathrm{DxH}-800$ and another automated cell counter technology that is routinely used in laboratories. ${ }^{18}$ Furthermore, apart from enumeration, examination of blood films prepared using DxH-SMS differentiation showed quality comparable with those prepared manually. ${ }^{15}$ However, no study has investigated the effects of the numbers of NRBCs in $\beta$-thalassemia/HbE patients on lymphocyte counts obtained using the UniCel DxH-800. Knowing the limitations of an automated cell counter is important to managing laboratory routine. In the present study, in both healthy volunteers and $\beta$-thalassemia/HbE patients, lymphocyte counts correlated well whether they were obtained using a UniCel DxH-800 or the standard flow cytometry approach, suggesting that the UniCel DxH-800 performs well. However, despite the high accuracy, a high degree of discrepancy was observed between lymphocyte counts obtained using standard flow cytometry and those obtained using the UniCel DxH-800 in $\beta$-thalassemia/HbE patients who had NRBCs > 100,001 cells $/ \mu \mathrm{L}$. In this group, the plot showed that the difference between the methods tended to increase as the average increased. Collectively, these data suggest the influence of a high number of NRBCs on the lymphocyte counts obtained using the UniCel DxH-800. This finding was similar to those of previous studies, which suggest that the performance of the DxH-800 in leukocyte counts must be improved. ${ }^{21,27}$ The results of the present study suggested that the interpretation of lymphocyte counts made to monitor the immune systems of $\beta$-thalassemia/HbE patients who have increased NRBC numbers should carefully consider variations that may occur due to the methodology used. Accurate leukocyte counts are important in $\beta$-thalassemia for several reasons. First, infection is a common complication and a major cause of death in $\beta$-thalassemia/HbE patients, making monitoring of WBC counts necessary to diagnose this complication in these patients. ${ }^{28}$ Second, accurate, reliable leukocyte and lymphocyte enumeration is essential to managing HIV-infected $\beta$-thalassemia patients. $^{29}$

Having demonstrated the influence of high numbers of NRBCs on lymphocyte counts obtained using the UniCel DxH-800, we next sought to determine whether high numbers of NRBCs interfered with lymphocyte classification. The results showed a mixed population of lymphocytes and NRBCs according to their FSC and SSC characteristics, suggesting that physical characteristics cannot be used to discriminate between lymphocytes and NRBCs. This finding is important in explaining the discrepancies in lymphocyte counts between the UniCel DxH-800 and standard flow cytometry in specimens that had high numbers of NRBCs. The principle behind automated cell counters is based on electrical impedance when each cell passes through a small aperture, which causes an electronic pulse. ${ }^{30-32}$ The size and number of pulses, respectively, indicate cell volume and number of cells. To enumerate leukocytes, the RBCs are lysed using the lysis buffer before counting and sizing. The differentiation of the leukocyte population is determined using data 
on both impedance and optical measurement. Considering the presence of high non-lytic NRBCs in a differential scatter gram could result in increased leukocyte counts. In contrast to the automated counter approach, the flow cytometry approach uses the molecular marker of the leukocyte, CD45, to classify the leukocyte population and differentiate leukocytes from non-leukocytes. This approach increases the accuracy when enumerating the leukocyte population. ${ }^{33}$ To address this limitation of automated cell counters, a new model of automated cell counter integrates advanced technology to improve the accuracy of leukocyte enumeration. Several studies have demonstrated the efficiency of this technology. ${ }^{11,20,21}$ It is important to evaluate the efficiency of this technology in specimens that have high numbers of NRBCs, particularly in $\beta$-thalassemia/HbE patients.

One might wonder whether the variability observed in the present study is due to the inaccuracy of NRBC counting. However, the accuracy of NRBC counts in the study's $\beta$-thalassemia/HbE patients is supported by the good agreement and excellent correlation between \%NRBC counts using the DxH-800 and those obtained using the manual approach. A study comparing the accuracy of NRBC counts in $\beta$-thalassemia patients showed that the absolute and \%NRBCs obtained using the Sysmex XE-2100 and the Advia 2120i were comparable to those obtained using manual microscopy and flow cytometry. ${ }^{34}$

The present study had several limitations. Although modern automated cell counters are available on the market, the present study focused only on evaluating the performance of the $\mathrm{DxH}-800$ instrument against that of flow cytometry. ${ }^{35,36}$ This was because the $\mathrm{DxH}-800$ instrument is currently being used in our laboratory. In addition, the present study examined the increased number of NRBCs only in $\beta$-thalassemia/ $\mathrm{HbE}$ disease. Apart from $\beta$-thalassemia/ $\mathrm{HbE}$ disease, other types of patients have shown increased numbers of NRBCs in their peripheral blood circulation, including cancer patients and pediatric patients, but the present study did not examine these patients. ${ }^{6,7}$ Further studies are needed to confirm the influence of NRBCs on the lymphocyte counts obtained using automated cell counters.

In summary, the results of the present study demonstrated good performance by the UniCel DxH-800. However, these results also detected that the number of NRBCs could interfere with the accuracy of lymphocyte counts when the number of NRBCs reached 100,001 cells/ $\mu \mathrm{L}$. Therefore, in specimens that have high numbers of NRBCs, manual examination is recommended to confirm the lymphocyte counts.

\section{Acknowledgements}

The authors thank the Faculty of Medicine Siriraj Hospital, Mahidol University, and the National Health Security Office, Thailand Ministry of Public Health, for supporting the research project. This project was also supported by the Thailand Research Fund (TRF) - Distinguished Research Professor Grant, grant number DPG5980001.

\section{Conflict of interest}

The authors have no conflict of interest to declare.

\section{Author contributions}

- ST performed the experiment, analyzed the data and drafted the manuscript

- SA collected the samples

- SL performed the experiment and analyzed the data

- KM contributed to the design and implementation of the research

- KP designed the experiment, evaluated and edited the manuscript

- EN analyzed the data, interpreted the results and wrote the manuscript.

- All authors discussed the results and commented on the manuscript.

\section{References}

1. Olsen Saraiva Camara N, Lepique AP, Basso AS. Lymphocyte differentiation and effector functions. Clin Dev Immunol. 2012;2012: 510603.

2. Larosa DF, Orange JS. 1. Lymphocytes. J Allergy Clin Immunol. 2008; 121(2 Suppl):S364-9; quiz S412.

3. Paul S, Lal G. The Molecular Mechanism of Natural Killer Cells Function and Its Importance in Cancer Immunotherapy. Front Immunol. 2017;8:1124.

4. Koyasu S, Moro K. Role of innate lymphocytes in infection and inflammation. Front Immunol. 2012;3:101.

5. Cronkite DA, Strutt TM. The Regulation of Inflammation by Innate and Adaptive Lymphocytes. J Immunol Res. 2018;2018:1467538.

6. Constantino BT, Cogionis B. Nucleated RBCs-Significance in the Peripheral Blood Film. Lab Med. 2000;31(4):223-9.

7. Danise P, Maconi M, Barrella F, Di Palma A, Avino D, Rovetti A, et al. Evaluation of nucleated red blood cells in the peripheral blood of hematological diseases. Clin Chem Lab Med. 2011;50(2):357-60.

8. Tantanate C, Klinbua C. Performance evaluation of the automated nucleated red blood cell enumeration on Sysmex XN analyser. Int J Lab Hematol. 2015;37(3):341-5.

9. Igout J, Fretigny M, Vasse M, Callat MP, Silva M, Willemont L, et al. Evaluation of the coulter LH 750 haematology analyzer compared with flow cytometry as the reference method for WBC, platelet and nucleated RBC count. Clin Lab Haematol. 2004;26(1):1-7.

10. de Keijzer $\mathrm{MH}$, van der Meer W. Automated counting of nucleated red blood cells in blood samples of newborns. Clin Lab Haematol. 2002;24(6):343-5.

11. Hwang DH, Dorfman DM, Hwang DG, Senna P, Pozdnyakova O. Automated Nucleated RBC Measurement Using the Sysmex XE-5000 Hematology Analyzer: Frequency and Clinical Significance of the Nucleated RBCs. Am J Clin Pathol. 2016;145(3):379-84.

12. Gulati GL, Bourne S, El Jamal SM, Florea AD, Gong J. Automated Lymphocyte Counts vs Manual Lymphocyte Counts in Chronic Lymphocytic Leukemia Patients. Lab Med. 2011;42(9):545-8.

13. Nicholson JK, Stein D, Mui T, Mack R, Hubbard M, Denny T. Evaluation of a method for counting absolute numbers of cells with a flow cytometer. Clin Diagn Lab Immunol. 1997;4(3):309-13.

14. Simson E, Groner W. Variability in absolute lymphocyte counts obtained by automated cell counters. Cytometry. 1995;22(1):26-34.

15. Brown W, Keeney M, Hedley BD. Initial performance evaluation of the UniCel(R) DxH slide maker/stainer Coulter(R) cellular analysis system. Int J Lab Hematol. 2014;36(2):172-83.

16. Barnes PW, Eby CS, Shimer G. Blast flagging with the UniCel DxH 800 Coulter Cellular Analysis System. Lab Hematol. 2010;16(2):23-5.

17. Hedley BD, Keeney M, Chin-Yee I, Brown W. Initial performance evaluation of the UniCel(R) DxH 800 Coulter(R) cellular analysis system. Int J Lab Hematol. 2011;33(1):45-56. 
18. Tan BT, Nava AJ, George TI. Evaluation of the Beckman Coulter UniCel DxH 800 and Abbott Diagnostics Cell-Dyn Sapphire hematology analyzers on pediatric and neonatal specimens in a tertiary care hospital. Am J Clin Pathol. 2011;135(6):929-38.

19. Meintker L, Ringwald J, Rauh M, Krause SW. Comparison of automated differential blood cell counts from Abbott Sapphire, Siemens Advia 120, Beckman Coulter DxH 800, and Sysmex XE-2100 in normal and pathologic samples. Am J Clin Pathol. 2013;139(5):641-50.

20. Bruegel M, Nagel D, Funk M, Fuhrmann P, Zander J, Teupser D. Comparison of five automated hematology analyzers in a university hospital setting: Abbott Cell-Dyn Sapphire, Beckman Coulter DxH 800, Siemens Advia 2120i, Sysmex XE-5000, and Sysmex XN-2000. Clin Chem Lab Med. 2015;53(7):1057-71.

21. Da Rin G, Vidali M, Balboni F, Benegiamo A, Borin M, Ciardelli ML, et al. Performance evaluation of the automated nucleated red blood cell count of five commercial hematological analyzers. Int J Lab Hematol. 2017;39(6):663-70.

22. Carr J, Geesaman S, Czader M. Performance Evaluation of the New UniCel DxH800 Coulter Cellular Analysis System in a Large Hospital Setting. Lab Med. 2012;43(5):157-63.

23. Laosombat V, Fucharoen SP, Panich V, Fucharoen G, Wongchanchailert M, Sriroongrueng W, et al. Molecular basis of beta thalassemia in the south of Thailand. Am J Hematol. 1992;41(3):194-8.

24. Nillakupt $K$, Nathalang $O$, Arnutti P, Jindadamrongwech S, Boonsiri T, Panichkul S, et al. Prevalence and hematological parameters of thalassemia in Tha Kradarn subdistrict Chachoengsao Province, Thailand. J Med Assoc Thai. 2012;95 Suppl 5:S124-32.

25. McGann PT, Nero AC, Ware RE. Clinical Features of beta-Thalassemia and Sickle Cell Disease. Adv Exp Med Biol. 2017;1013:1-26.

26. Noulsri E, Ardsiri S, Lerdwana S, Pattanapanyasat K. Comparison of Phosphatidylserine-Exposing Red Blood Cells, Fragmented Red Blood Cells and Red Blood Cell-Derived Microparticles in $\beta$-Thalassemia/ $\mathrm{HbE}$ Patients. Lab Med. 2018:Imy039-lmy.
27. Hotton J, Broothaers J, Swaelens C, Cantinieaux B. Performance and Abnormal Cell Flagging Comparisons of Three Automated Blood Cell CountersCell-Dyn Sapphire, DxH-800, and XN-2000. Am J Clin Pathol. 2013;140(6):845-52.

28. Wanachiwanawin W. Infections in E-beta thalassemia. J Pediatr Hematol Oncol. 2000;22(6):581-7.

29. Tiensiwakul P, Boonmongkol P, Nonsee N, Bunchontevakul S, Desudchit P. Application of flow cytometric beads for simultaneous CD4 and CD8 determinations in HIV-1 infected thalassemia patients. J Med Assoc Thai. 2009;92(3):398-404.

30. DeNicola DB. Advances in hematology analyzers. Top Companion Anim Med. 2011;26(2):52-61.

31. Green R, Wachsmann-Hogiu S. Development, history, and future of automated cell counters. Clin Lab Med. 2015;35(1):1-10.

32. Chabot-Richards DS, George TI. White blood cell counts: reference methodology. Clin Lab Med. 2015;35(1):11-24.

33. Kalva Borato DC, Carraro E, Weber Ribas SR, Kalva-Filho CA, Rebuglio Vellosa JC. Comparison of two methodologies for CD4(+) T lymphocytes relative counting on immune monitoring of patients with human immunodeficiency virus. ScientificWorldJournal. 2012;2012: 906873.

34. Karakukcu M, Karakukcu C, Unal E, Ozturk A, Ciraci Z, Patiroglu T, et al. The Importance of Nucleated Red Blood Cells in Patients with Beta Thalassemia Major and Comparison of Two Automated Systems with Manual Microscopy and Flow Cytometry. Clin Lab. 2015;61(9):1289-95.

35. Rastogi P, Bhatia P, Varma N. Novel Automated Hematology Parameters in Clinical Pediatric Practice. Indian Pediatr. 2017;54(5):395-401.

36. Ben-Yosef Y, Marom B, Hirshberg G, D'Souza C, Larsson A, Bransky A. The HemoScreen, a novel haematology analyser for the point of care. J Clin Pathol. 2016;69(8):720-5. 